\title{
Displaced subcapital fracture of the hip in transient osteoporosis of pregnancy
}

\section{A case report}

\author{
S. K. Fokter, V. Vengust \\ Department for Orthopaedic Surgery and Sports Trauma, Celje General Hospital, Celje, Slovenia
}

Accepted: 23 September 1996

Summary. We describe a case of displaced subcapital fracture of the hip in a woman in the third trimester of her first pregnancy. A pathological fracture occurred in a previously painful hip, and radiographs showed pronounced osteopenia of the femoral head and neck. Closed reduction and internal fixation was carried out 2 weeks after delivery when the osteopenia was still severe. Healing of the fracture followed with recovery of hip movements.

Résumé. Nous décrivons un cas de fracture souscapitale de la hanche, chez une femme dans son troisième trimestre de sa première grossesse. La fracture pathologique s'est produite sur une hanche, préalablement douloureuse. En radiographiant la lèsion, la déminéralisation osseuse de la tete et du col du fémur a été constatée. Le traitement chirurgical par réduction et ostéosynthése, deux semaines après l'accouchement, alons que l'insuffisance mentionée était encore bien expressive, a conduit à une consolidation efficace. Ce traitement favorise aussi les mouvements d'articulation de la hanche.

\section{Introduction}

Transient osteoporosis of the hip is uncommon and only 6 pathological fractures of the proximal femur have been reported in association with it since

Reprint requests to: S. K. Fokter, Department for Orthopaedic Surgery and Sports Trauma, Celje General Hospital, Oblakova 5, SLO-3000 Celje, Slovenia
$1959[2,3,5,9,14]$. One of the 2 displaced fractures was treated successfully by open reduction and internal fixation after delivery when the osteopenia was most severe [5]. We present a further case.

\section{Case report}

A woman, 30 years of age, was seen during the 27th week of her first pregnancy. She had had pain in her left groin, which was worse on walking, for the previous 4 weeks. Her medical history was normal and there had been no injury. She was tender over the buttock and greater trochanter. Straight leg raising was positive on the left. There were no abnormal neurological signs. Active and passive movements of her left hip were good. She was thought to have mild sciatica associated with her pregnancy. She was admitted to hospital for 3 days for bed rest and physiotherapy. She had less pain when she was discharged, but her symptoms recurred with normal activity and she had to use crutches for walking.

Four weeks later, she fell while walking with crutches and the pain in her groin became much worse. An anteroposterior radiograph showed a displaced subcapital fracture at the left hip (Fig. 1). She was admitted again and 2 days later a normal baby was delivered by Caesarean section. A bone scan showed increased uptake in the left femoral neck, and also in the knee and ankle. Aspiration of the left hip yielded $12 \mathrm{ml}$ of serosanguineous fluid without abnormal cells, and anaerobic and aerobic cultures showed no growth. The blood count, serum calcium, phosphate, alkaline phosphatase and cancero-embryonal antigen level were all normal.

Twelve days after delivery, closed reduction and fixation with 3 screws was carried out under fluoroscopic control. A hip spica cast was applied for 5 weeks because of the poor bone quality (Fig. 2). The cast was then removed and nonweightbearing with crutches allowed.

Four months after the operation, radiographs showed increased mineralisation of the femoral head and neck, and healing of the fracture (Fig. 3). She was then allowed to walk without crutches. 


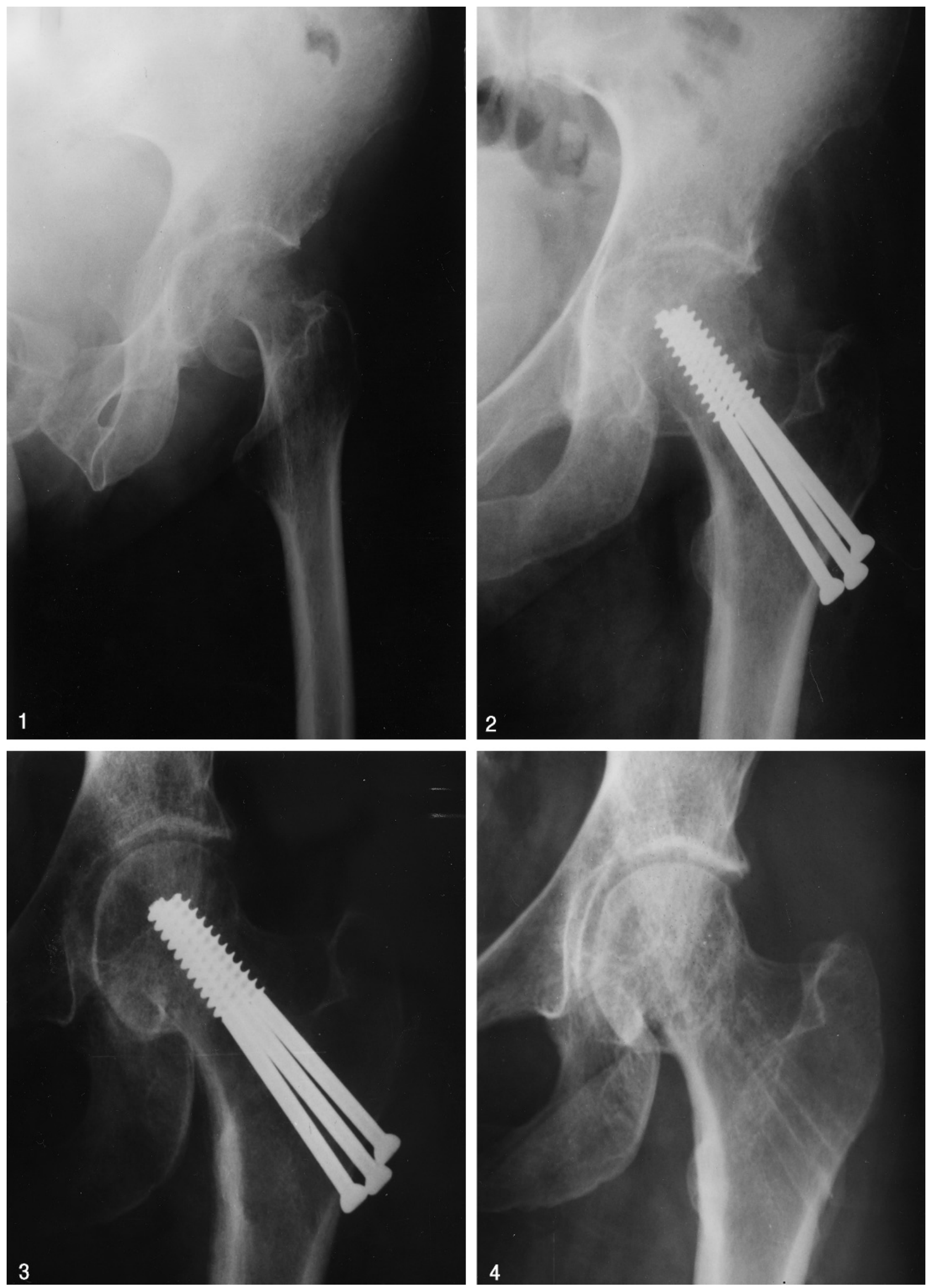


One year after operation, she did not limp and the hip had full extension, flexion to $95^{\circ}$, external rotation to $25^{\circ}$ and internal rotation to $20^{\circ}$ (both in extension), abduction was $25^{\circ}$ and adduction $20^{\circ}$. The screws were removed and radiographs showed normal mineralisation of the proximal femur (Fig. 4).

\section{Discussion}

The cause of the osteopenia in transient osteoporosis of the hip in pregnancy is not known $[1,6]$. Pain typically comes on gradually during the last trimester of pregnancy, and is localised to the groin, greater trochanter and anterior part of the thigh. Active and passive movements of the hip are usually full, and laboratory tests are normal, apart from a raised sedimentation rate and urinary hydroxyproline level [10]. Bone scans show increased uptake in the proximal femur shortly after the onset of symptoms [7]. MRI has been reported as showing abnormalities within 48 hours after the onset of symptoms [4]: T1-weighted images show low signal intensity with high signal intensity in the T2-weighted images, the pattern of bone marrow oedema [11, 12, 13]. Radiographic changes are not evident until 3 to 6 weeks after the onset of symptoms. The diagnosis is usually made by exclusion of neoplasm, infection, reflex sympathetic dystrophy and avascular necrosis [8]. The clinical course is benign, and symptoms usually resolve with radiographic findings returning to normal in 3 to 6 months [3].

Pathological fractures are the most serious complication of the condition. One of 2 patients reported by Brodell et al had a subcapital fracture with postero-inferior displacement of the femoral head [2]. Treatment was at first conservative, but after 6 weeks when radiographs showed increased mineralisation, a valgus derotation osteotomy was performed with a successful outcome. The patient described by Fingeroth had a subcapital fracture which might have displaced during a grand mal seizure 3 weeks before open reduction and fixation with 3 cannulated screws, carried out 5 days after delivery [5]. The fracture healed and function was excellent 3 years later.

Fig. 1. Anteroposterior radiograph of the left hip before delivery showing a displaced subcapital fracture

Fig. 2. Radiograph after reduction and fixation with 3 cannulated screws

Fig. 3. Increased mineralisation and healing of the fracture 4 months after operation

Fig. 4. After removal of the screws one year after operation
Our patient was also operated on 3 weeks after fracture. The bone was found to be markedly osteopenic during fixation which was why we used a hip spica. The fracture healed with an excellent result, demonstrating that osteopenic bone in transient osteoporosis of pregnancy has normal healing potential.

\section{References}

1. Bramlett KW, Killian JT, Nasca RJ, Daniel WW (1987) Transient osteoporosis. Clin Orthop 222: 197-202

2. Brodell JD, Burns JE Jr, Heiple KG (1989) Transient osteoporosis of the hip in pregnancy. Two cases complicated by pathological fracture. J Bone Joint Surg [Am] 71: $1252-1257$

3. Curtiss PH Jr, Kincaid WE (1959) Transitory demineralization of the hip in pregnancy. A report of three cases. J Bone Joint Surg [Am] 41: 1327-1333

4. Daniel WW, Sanders PC, Alarcón GS (1992) The early diagnosis of transient osteoporosis by magnetic resonance imaging. A case report. J Bone Joint Surg [Am] 74: $1262-1264$

5. Fingeroth RJ (1995) Successful operative treatment of a displaced subcapital fracture of the hip in transient osteoporosis of pregnancy. A case report and review of the literature. J Bone Joint Surg [Am] 77: 127-131

6. Guerra JJ, Steinberg ME (1995) Distinguishing transient osteoporosis from avascular necrosis of the hip. J Bone Joint Surg [Am] 77: 616-624

7. Gaucher A, Colomb JM, Naoun A, Faure G, Netter P (1979) The diagnostic value of $99 \mathrm{~m}$ Tc-diphosponate bone imaging in transient osteoporosis of the hip. J Rheumatol 6: $574-583$

8. Schapira D (1992) Transient osteoporosis of the hip. Sem Arthrit Rheumatol 22: 98-105

9. Shifrin LZ, Reis ND, Zinman H, Besser MI (1987) Idiopathic transient osteoporosis of the hip. J Bone Joint Surg [Br] 69: 769-773

10. Takatory Y, Kokubo T, Ninomiya T, Okutsu I, Kamogawa M (1991) Transient osteoporosis of the hip. Magnetic resonance imaging. Clin Orthop 271: 190-194

11. Tamburrini O, Sessa M, Della-Salla M, Stana C, De Caridi A, Carallo OF (1995) Transient osteoporosis of the hip in magnetic resonance imaging. Radiol Med Torino 90: $187-193$

12. Urbanski SR, De Lange EE, Eschenroeder HC Jr (1992) Magnetic resonance imaging of transient osteoporosis of the hip. A case report. J Bone Joint Surg [Am] 73: $451-455$

13. Wilson AJ, Murphy WA, Hardy DC, Totty WG (1988) Transient osteoporosis: transient bone marrow edema? Radiology 167: 757-760

14. Zasacki W (1993) Transient osteoporosis of the hip. Pol Tyg Lek 48 Suppl 3: 43-45 